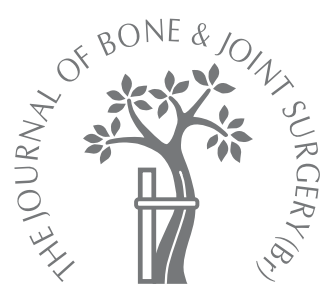

\title{
Evaluation of two surgical techniques for acetabular reconstruction in total hip replacement for congenital hip disease
}

\author{
RESULTS AFTER A MINIMUM TEN-YEAR FOLLOW-UP
}

G. Hartofilakidis,
G. Georgiades,
G. C. Babis,
C. K. Yiannakopoulos

From the University of Athens Medical

School, Athens, Greece
G. Hartofilakidis, MD, FACS, Emeritus Professor of Orthopaedics

University of Athens Medical School, 21 Fotiou, Patriarchou Street, Athens 11471, Greece.

In. Georgiades, MD, Consultant Orthopaedic Surgeon

Orthopaedic Department Tripoli Hospital, 31

Kousianofsky Street, N.

Psychiko, Athens 11525

Greece.

G. C. Babis, MD, Assistant Professor

First Orthopaedic Department University of Athens Medical School, 5 Heraklitou Street, Dionysos, Athens 14576 , Greece.

In. K. Yiannakopoulos, MD, Consultant Orthopaedic Surgeon

First Orthopaedic Department University of Athens Medical School, 2 Byzantiou Street, Nea Smyrni, Athens 17121, Greece.

Correspondence should be sent to Professor G. Hartofilakidis; e-mail: gephge@ hotmail.com

(C)2008 British Editorial Society of Bone and Joint Surgery doi:10.1302/0301-620X.90B6 $20490 \$ 2.00$

$J$ Bone Joint Surg $[\mathrm{Br}]$ 2008;90-B:724-30 Received 14 November 2007; Accepted after revision 13 February 2008

\begin{abstract}
We have evaluated the results of total hip replacement in patients with congenital hip disease using 46 cemented all-polyethylene Charnley acetabular components implanted with the cotyloplasty technique in 34 patients (group A), and compared them with 47 metalbacked cementless acetabular components implanted without bone grafting in 33 patients (group B). Patients in group A were treated between 1988 and 1993 and those in group B between 1990 and 1995. The mean follow-up for group $A$ was 16.6 years (12 to 18) and the mean follow-up for group $B$ was 13.4 years (10 to 16 ).

Revision for aseptic loosening was undertaken in 15 hips (32.6\%) in group $A$ and in four hips $(\mathbf{8 . 5} \%)$ in group $B$. When liner exchange was included, a total of 13 hips were revised in group $B(27.7 \%)$. The mean polyethylene wear was $0.11 \mathrm{~mm} / \mathrm{yr}(0.002$ to 0.43$)$ and $0.107 \mathrm{~mm} / \mathrm{yr}$ (0 to 0.62 ) for groups $A$ and $B$, respectively. Polyethylene wear in group $A$ was associated with linear osteolysis, and in group B with expansile osteolysis.

In patients with congenital hip disease, when $80 \%$ cover of the implant can be obtained, a cementless acetabular component appears to be acceptable and provides durable fixation. However, because of the type of osteolysis arising with these devices, early exchange of a worn liner is recommended before extensive bone loss makes revision surgery more complicated.
\end{abstract}

Reconstruction of the acetabulum during total hip replacement (THR) in congenital hip disease may be problematic. The difficulties encountered at operation may vary depending on the local anatomical abnormalities present in the three types of congenital hip disease, i.e., dysplasia, low dislocation and high dislocation ${ }^{1}$ (Table I), and are reflected in the results of surgery.

Several techniques have been described to overcome the problems of acetabular deficiency at THR when cover of the acetabular component with host bone is not complete. Those most commonly used are augmentation of the superolateral aspect of the acetabular rim with a bulk bone graft, ${ }^{2}$ placement of the acetabular component to create a high hip centre, ${ }^{3}$ medialisation of the hip centre by employing the cotyloplasty technique, ${ }^{1}$ and the use of hemispherical, small-diameter, metalbacked cementless components with or without bone grafting. ${ }^{4}$

The purpose of this study was to evaluate the results after a minimum of ten years follow-up (10 to 18) of two surgical techniques. Firstly, the cotyloplasty technique, which involves medialisation of the acetabular floor by creating a controlled comminuted fracture of the entire medial wall, impaction of autogenous morcellised bone graft, and implantation of a small all-polyethylene acetabular component of the Charnley series with cement (Fig. 1a), or secondly the use of a hemispherical cementless, small-diameter, modular metal-backed acetabular component without bone grafting (Fig. 1b). The latter procedure has been undertaken since 1990, when metal-backed prostheses were introduced into our hospital, provided at least $80 \%$ cover of the implant with host bone could be obtained in the true acetabulum. ${ }^{5,6}$

\section{Patients and Methods}

In 99 consecutive THRs in 73 patients with congenital hip disease, the acetabulum was replaced either by a moulded all-polyethylene Charnley component (DePuy, Leeds, United Kingdom) fixed with cement (Simplex P; Howmedica, Rutherford, New Jersey) after cotyloplasty (49 hips in 37 patients, group A) during the period 1988 to 1993 , or by a modular hemispherical, metal-backed non-cemented porous-coated titanium component, without bone grafting (50 hips in 36 patients, group B) 
Table I. Classification system of congenital hip disease in adults according to Hartofilakidis et al ${ }^{1,5,6}$

\begin{tabular}{|c|c|c|}
\hline Type & Description & Pathoanatomy of the acetabulum (verified during surgery) \\
\hline Dysplastic hip & $\begin{array}{l}\text { The femoral head is contained within the original } \\
\text { acetabulum despite the degree of subluxation }\end{array}$ & $\begin{array}{l}\text { Segmental deficiency of the superior wall. Secondary } \\
\text { shallowness due to fossa-covering osteophyte }\end{array}$ \\
\hline Low dislocation & $\begin{array}{l}\text { The femoral head articulates with a false acetabulum } \\
\text { that partially covers the true acetabulum }\end{array}$ & $\begin{array}{l}\text { Complete absence of the superior wall. Anterior and posterior } \\
\text { segmental deficiency. Narrow opening and inadequate depth } \\
\text { (true acetabulum) }\end{array}$ \\
\hline High dislocation & $\begin{array}{l}\text { The femoral head is completely out of the true } \\
\text { acetabulum and has migrated superiorly and posteriorly }\end{array}$ & $\begin{array}{l}\text { Segmental deficiency of the entire acetabular rim } \\
\text { Narrow opening } \\
\text { Inadequate depth } \\
\text { Abnormal distribution of bone stock, mainly located } \\
\text { superoposteriorly (true acetabulum) }\end{array}$ \\
\hline
\end{tabular}

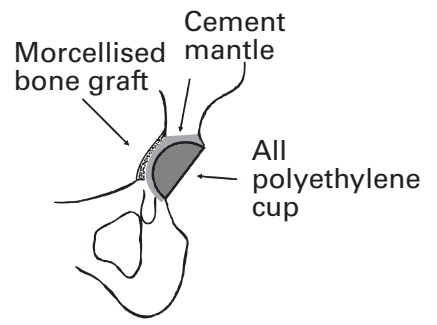

Fig. 1a

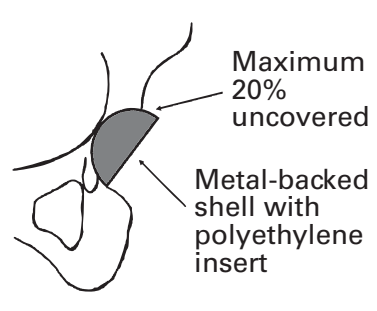

Fig. 1b
Diagrams of the two surgical techniques used to reconstruct the acetabulum in congenital hip disease, when complete coverage of the acetab ular component by host bone cannot be obtained, a) the cotyloplasty technique, and b) the use of a cementless, modular metal-backed acetabular component, without bone grafting.

between 1990 and 1995. Two patients (two hips) from group A and one patient (one hip) from group B were excluded from the study because they did not attend for follow-up, as well as one patient (one hip) from group A and two patients (two hips) from group B because of infection. Thus, in the final evaluation there were 33 patients (46 hips) in group A and 34 patients (47 hips) in group B. The age of the patient, their gender, weight, height and the pre-operative diagnoses are listed in Table II. Two patients (two hips) from group A and three patients (four hips) from group B died at five (three patients) and eight (two patients) years after operation, at which stage they were all asymptomatic.

The patients included in the study represent a consecutive non-selected group operated on by the senior author $(\mathrm{GH})$, using a transtrochanteric approach, and in all cases the acetabular component was placed at the level of the true acetabulum. In group $\mathrm{A}$, the offset-bore acetabular component with an external diameter of $35 \mathrm{~mm}$ and a $10 \mathrm{~mm}$ thickness of polyethylene in the upper weight-bearing part was used in 40 hips, and the long posterior wall small component, with an external diameter of $47 \mathrm{~mm}$, and a $8.9 \mathrm{~mm}$ thickness of polyethylene was used in six. On the femoral side, the cemented monoblock Charnley prosthesis was used for 30 hips and the Harris CDH modular prosthesis (Zimmer, Warsaw, Indiana) for 16 hips. In all cases the diameter of the femoral head was $22.25 \mathrm{~mm}$. In group B, the Opti-Fix modular hemispherical press-fit metal-backed, cementless acetabular component (Smith and Nephew, Memphis, Tennessee) was used in 32 hips and the HarrisGalante I component (Zimmer) in 15. Both of these were in common use in the early 1990s. They had several holes for screw fixation and shared a similar locking mechanism for the acetabular inserts. All acetabular components were press-fitted after under-reaming of the acetabulum by $2 \mathrm{~mm}$; 19 were also fixed with two or three screws when improvement of rotational stability was needed. The mean external diameter of the Opti-Fix component was $44.56 \mathrm{~mm}$ (40 to 56) and of the Harris-Galante I implant was $43 \mathrm{~mm}$ (42 to 44). The mean thickness of the polyethylene in the two types of acetabular component, according to the manufacturer's information, was $5.14 \mathrm{~mm}$ (4 to 8 ), and $6.28 \mathrm{~mm}$ (6.1 to 7.1), respectively. For the femoral reconstruction a cemented component was used in all hips, which was modular in 38 ( 22 of the Opti-Fix hip and 16 of the Harris CDH hip), and a monoblock Charnley in nine. The diameter of the metal femoral head was $22.25 \mathrm{~mm}$ in 38 hips, $26 \mathrm{~mm}$ in five, and $28 \mathrm{~mm}$ in four. All the femoral heads with a diameter of $26 \mathrm{~mm}$ or $28 \mathrm{~mm}$ were used with acetabular components which had an external diameter greater than $48 \mathrm{~mm}$.

Follow-up evaluation. The patients were examined at three, six and 12 months post-operatively, and once-yearly thereafter. Clinical evaluation was performed using the Merle d'Aubigné and Postel scale as modified by Charnley. ${ }^{7}$ Radiologically, the hips were assessed with anteroposterior pelvic radiographs taken soon after operation and those obtained at the latest follow-up examination. Three parameters were evaluated: linear wear, peri-acetabular osteolysis and acetabular loosening. Polyethylene wear was determined as described by Livermore, Ilstrup and Morrey. ${ }^{8}$ To measure the linear polyethylene wear in the offset-bore cemented acetabular components, because of the asymmetry of the polyethylene and the unknown direction of the linear penetration in any particular case, we used the methods of Charnley and Halley ${ }^{9}$ and Wroblewski. ${ }^{10}$

Osteolysis was assessed around the acetabular component on the latest radiograph by the presence of radiolucent lines and expansile osteolytic lesions, which were recorded 
Table II. The demographic details of both groups

\begin{tabular}{|c|c|c|c|c|c|c|c|c|c|}
\hline \multirow[b]{2}{*}{ Group } & \multirow[b]{2}{*}{$\begin{array}{l}\text { Number of } \\
\text { patients (hips) }\end{array}$} & \multirow[b]{2}{*}{$\begin{array}{l}\text { Mean age in } \\
\text { yrs (range) }\end{array}$} & \multirow[b]{2}{*}{$\begin{array}{l}\text { Gender } \\
\text { (M:F) }\end{array}$} & \multirow[b]{2}{*}{$\begin{array}{l}\text { Mean weight } \\
\text { in kg (range) }\end{array}$} & \multirow[b]{2}{*}{$\begin{array}{l}\text { Mean height in } \\
\text { cm (range) }\end{array}$} & \multirow[b]{2}{*}{$\begin{array}{l}\text { Mean follow-up } \\
\text { in yrs (range) }\end{array}$} & \multicolumn{3}{|l|}{ Diagnosis $^{*}$} \\
\hline & & & & & & & Dysplasia & LD & HD \\
\hline$A$ & $34(46)$ & 50 (25 to 69 ) & $1: 33$ & 66.83 (48 to 89 ) & 156 (143 to 176$)$ & $16.6(12$ to 18$)$ & 4 & 15 & 27 \\
\hline B & 33 (47) & 47 (27 to 70$)$ & $2: 31$ & 62.21 (47 to 84 ) & 156 (140 to 167$)$ & $13.4(10$ to 16$)$ & 14 & 14 & 19 \\
\hline
\end{tabular}

according to the three zones described by DeLee and Charnley. ${ }^{11}$ Linear osteolysis was defined as the presence of a radiolucent space at the cement-bone or implant-bone interface of at least $1 \mathrm{~mm} \cdot{ }^{12,13}$ Expansile focal osteolysis was defined as a sharply-demarcated radiolucent space with a rounded or scalloped appearance extending away from the component. ${ }^{12}$ The approximate size of these lesions was measured with calipers in terms of their longest diameter and the widest diameter perpendicular to the defined longest axis. Magnification was corrected with the use of the known diameter of the femoral head.

Acetabular components were classified as loose when migration was $>2 \mathrm{~mm}$ in a vertical or horizontal direction, or there was a continuous radiolucent line $>1 \mathrm{~mm}$ wide at the cement-bone or the implant-bone interface.

Statistical analyses were performed with the Mann-Whitney $\mathrm{U}$ test for continuous variables and the chi-squared test with Yates' correction for categorical variables. The level of statistical significance was set at $p<0.05$. Survival analysis, to assess the life-span of the acetabular component in the two surgical techniques, was performed using the KaplanMeier method ${ }^{14}$ with the endpoint as revision of the acetabular component due to aseptic loosening. A separate survival curve was calculated for patients from group B, including in the endpoint isolated exchange of the liner for excess wear. The log-rank test was used to compare the survival of the two acetabular components.

\section{Results}

In group A 15 hips (32.6\%) had been revised for aseptic loosening at the final follow-up, compared with four $(8.5 \%)$ in group B (chi-squared test, $\mathrm{p}=0.004)$. In group A, the 15 loose acetabular components, all of the offset-bore type, were revised at a mean of 13.7 years ( 9 to 17) from the initial operation. In ten hips, only the acetabular component was revised, whereas in five both components were exchanged. In group B, four Opti-Fix acetabular components failed because of loosening of the metal shell and were revised at a mean of 11.3 years (10 to 13). The femoral components were also loose and were revised. Additionally, five hips in group B, all replaced using the Harris-Galante I acetabular component, had an isolated exchange of the liner a mean of 14.6 years (14 to 17) after surgery, because of polyethylene wear and peri-acetabular osteolysis. The metal shells were stable and were retained. In four more hips in group B (two of the Harris-Galante I type, and two of the Opti-Fix) the worn polyethylene liner was exchanged at the time of revision for aseptic loosening of the femoral component, at a mean of 10.2 years (6 to 15) after the initial procedure. In group B when aseptic acetabular loosening and liner exchange for wear and peri-acetabular osteolysis were combined, 13 hips $(27.7 \%)$ were revised. This rate of overall revision in group B was not significantly different from the rate found in group A (chi-squared test, $p=0.6)$.

In relation to the type of congenital hip disease, the revision rates for the dysplastic hips, the hips with low dislocation and those with high dislocation, from both groups combined, were $11 \%$ ( 2 of 18 ), $34.5 \%$ (10 of 29 ) and $34.8 \%$ (16 of 46$)$, respectively.

Of 13 failed acetabular components in group B, five had a polyethylene thickness ranging between $4 \mathrm{~mm}$ and $5 \mathrm{~mm}$, and eight between $6 \mathrm{~mm}$ and $8 \mathrm{~mm}$ (chi-squared test, $\mathrm{p}=0.1$.

The overall mean annual rate of wear of the acetabular components in group A was $0.11 \mathrm{~mm} / \mathrm{year}(0.002$ to 0.43 ), and in group B was $0.107 \mathrm{~mm} / \mathrm{year}$ (0 to 0.62 ) (MannWhitney $U$ test, $p=0.6$ ). The mean annual rate of wear of the 15 acetabular components revised for aseptic loosening in group A was $0.17 \mathrm{~mm} /$ year $(0.044$ to 0.43$)$, that of the four cases in group B was $0.31 \mathrm{~mm} /$ year $(0.012$ to 0.62$)$ (Mann-Whitney $\mathrm{U}$ test, $\mathrm{p}=0.4$ ). In the nine exchanged liners in group B the mean annual rate was $0.13 \mathrm{~mm} /$ year (0.036 to 0.204$)$.

Peri-acetabular osteolysis was observed in 16 hips $(34.8 \%)$ in group A, and in seven hips $(14.9 \%)$ in group B (chi-squared test, $\mathrm{p}=0.026$ ). The lytic lesions associated with the cemented acetabular components were linear in all cases, and in the 15 hips that required revision for loosening in group A, they were observed in all three zones. In one of these hips there was also an expansile lytic lesion in zone $1{ }^{11}$ The lytic lesions associated with the cementless acetabular components were localised and expansile in all cases. A total of 11 lytic lesions were observed in relation to seven cementless acetabular components. The lesions varied in size from $3 \mathrm{~mm} \times 5 \mathrm{~mm}$ to $18 \mathrm{~mm} \times 24 \mathrm{~mm}$; four were located in zone I, four in zone II, and three in zone III. ${ }^{11}$ Survival analysis. With revision of the acetabular component for aseptic loosening as the endpoint, the cumulative success rate of the components used after cotyloplasty was $95.4 \%$ (95\% CI 89.2 to 100$)$ at ten years when 42 hips were at risk and $81.5 \%$ (95\% CI 73.4 to 89.6$)$ at 14 years 


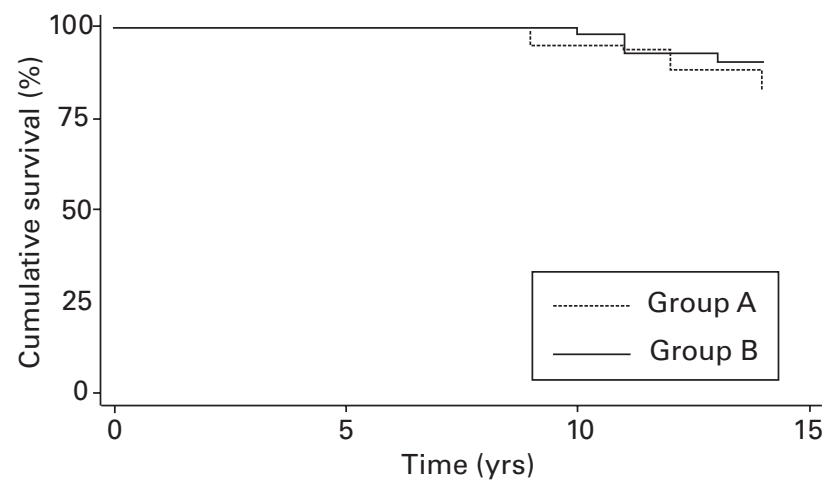

Fig. 2

Kaplan-Meier survival curves for both groups, with revision for aseptic loosening as the endpoint. In total, 42 acetabular components in group $A$ and 42.5 acetabular components in group $B$ were at risk in the nineto ten-year interval. In the 13- to 14-year interval the number of acetabular components at risk in the two groups were 38.5 and 24.5 , respectively.

when 38.5 hips were at risk. That of the cementless metalbacked components was $97.7 \%$ (95\% CI 93.3 to 100$)$ at ten years when 42.5 hips were at risk and $90.3 \%$ (95\% CI 83.9 to 96.7$)$ at 14 years when 24.5 hips were at risk (logrank test, $\mathrm{p}=0.29$ ) (Fig. 2). When liner exchange was included in the number of failures of the latter group, the cumulative success rate at ten years dropped to $90.8 \%$ (95\% CI 84.3 to 97.3 ) when 41 hips were at risk and at 14 years dropped to $69.5 \%$ (95\% CI 55.8 to 83.2) when 24 hips were at risk (log-rank test, $\mathrm{p}=0.19$ ) (Fig. 3).

The follow-up examination of the 22 patients (29 hips) of group A who retained the original acetabular component was undertaken at a mean of 16.6 years (13 to 18$)$ postoperatively and of the 28 patients ( 38 hips) from group B who retained the original acetabular component at a mean of 13.4 (12 to 16 ) (Figs 4 and 5).

For patients who retained the original component, the score for pain, on the modified Merle d'Aubigné and Postel scale improved from a mean of 2.6 points ( 1 to 4 ) preoperatively to a mean of 5.1 points ( 5 or 6 ) post-operatively for patients in group A, and in patients from group B from a mean of 2.8 points ( 2 to 4 ) to a mean of 5.5 points ( 5 or 6 ) for patients in group B. Similarly, the score for function improved in group A from a mean of 2.3 points ( 1 to 3 ) to a mean of five points (4 to 6), and in group B from a mean of 2.6 points ( 3 to 6 ) to a mean of 5.4 points ( 3 to 6 ). Finally, the score for movement in group A improved from a mean of three points ( 1 to 5 ) to a mean of 4.5 points ( 2 to 6 ), and in group B from a mean of 2.6 points ( 1 to 5 ) to a mean of 4.8 points ( 3 to 5 ).

\section{Discussion}

The major technical problem during total hip replacement in patients with congenital hip disease, especially in cases with low and high dislocation, is the reconstruction of the

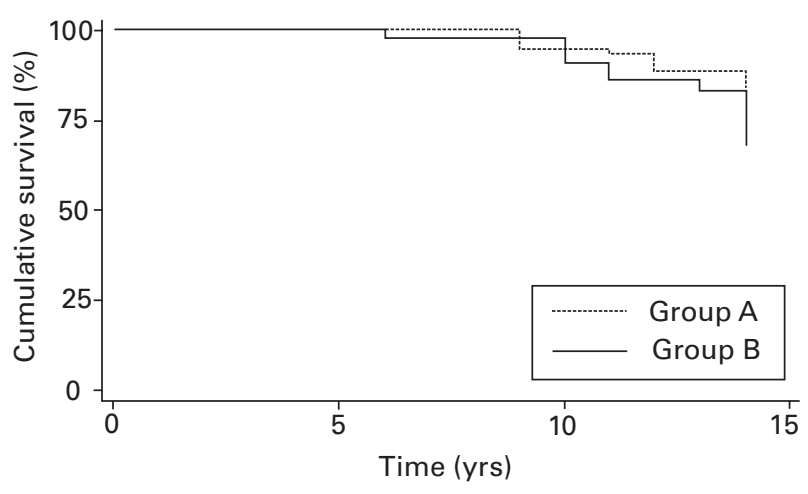

Fig. 3

Kaplan-Meier survival curves for both groups, with revision for any reason as the endpoint. In total, 42 acetabular components in group $A$ and 41 acetabular components in group B were at risk in the nineto ten-year interval. In the 13- to 14-year interval the number of acetabular components at risk in the two groups were 38.5 and 24, respectively.

acetabulum, given that the placement of the component at the level of the true acetabulum remains ideal for mechanical reasons. ${ }^{1,15,16}$ However, cover of the acetabular component with host bone and sufficient fixation at the level of the true acetabulum is not always possible. The use of a bulk structural autologous graft from the femoral head to augment the superolateral aspect of the acetabular rim was initially proposed by Harris et al. ${ }^{2}$ Although the short-term clinical results of this technique were excellent, the failure rate after approximately 12 years was high $(46 \%) .{ }^{17,18}$ This may be related to the complex pathoanatomy encountered at the level of the true acetabulum, and the abnormal distribution of stresses combined with the unfavourable longterm biological behaviour of structural grafts. ${ }^{5,19}$ A few authors supported proximal placement of the acetabular component, ${ }^{3,4}$ yet at a proximal level the lever arm for body weight is much longer than that of the abductors, resulting in excessive loading of the hip joint. In addition, at this level shearing forces acting on the acetabular component may lead to early loosening, ${ }^{6}$ and in unilateral cases a proximally-sited acetabular component perpetuates limping and limb-length discrepancy. ${ }^{5}$

Until 1990, in all THRs performed by us for congenital hip disease, and when complete cover of the acetabular component with host bone could not be obtained, a cotyloplasty was used. Since 1990, when metal-backed prostheses became available, cementless hemispherical modular metalbacked prostheses have been used without augmentation of the superolateral rim of the acetabulum, provided at least $80 \%$ cover of the implant with bone could be obtained. ${ }^{1,5,6}$

The limitations of this study are its retrospective nature, the use for technical reasons of two methods to measure polyethylene wear, the use of femoral heads with different diameters in a number of group B patients, and the longer follow-up for the cotyloplasty group (12 to 18 years) com- 


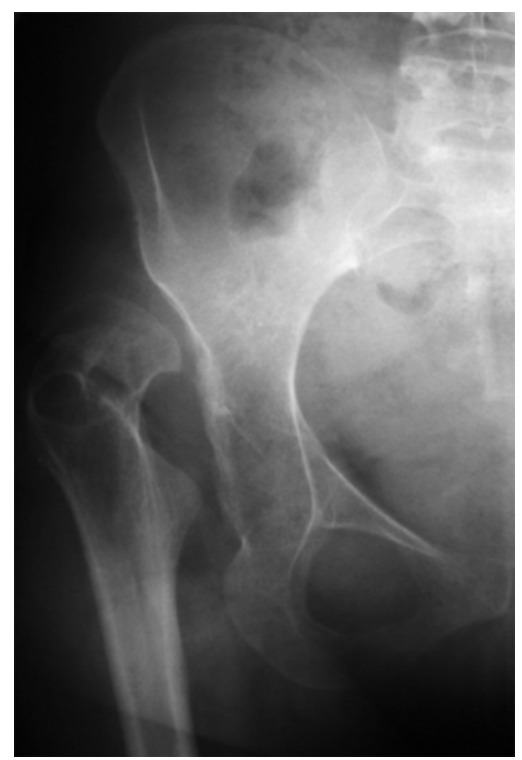

Fig. 4a

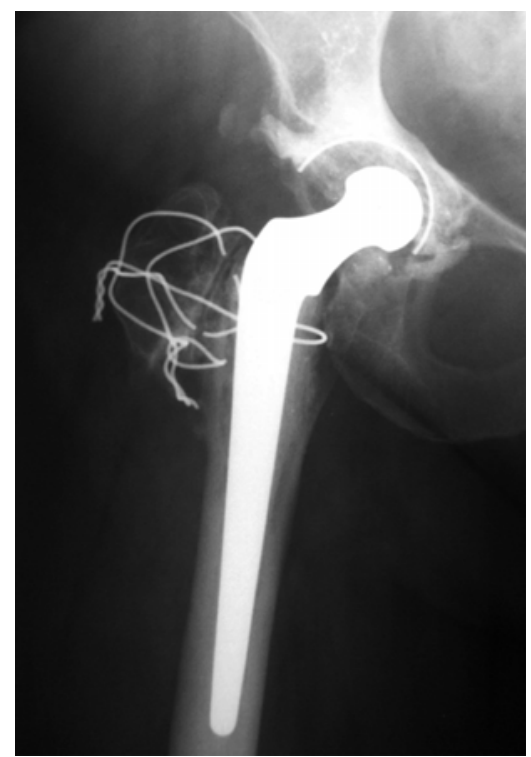

Fig. $4 b$

Anteroposterior radiographs of a 29-year-old woman with high dislocation of the right hip a) preoperative view and b) 17 years after total hip replacement. The Charnley offset-bore acetabular component is fixed with cement after cotyloplasty. The femoral component is of the Charnley CDH type.

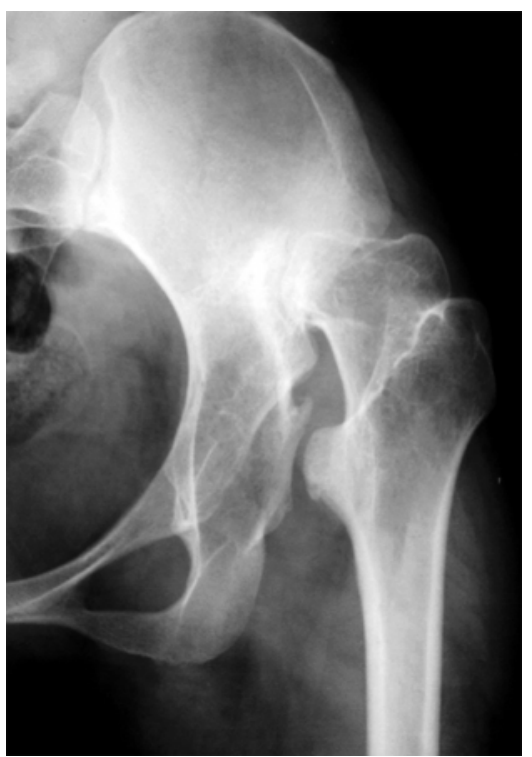

Fig. 5a

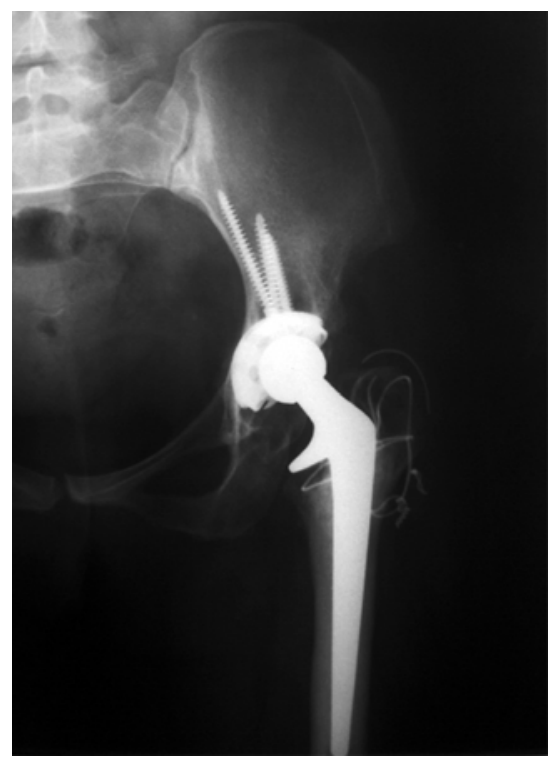

Fig. 5b

Anteroposterior radiographs of a 28-year-old woman with a high dislocation of the left hip a) preoperatively, and b) 16 years after hybrid total hip replacement. The acetabular component is of the HarrisGalante I type and the femoral component is of the Harris CDH variety.

pared with that for the cementless group (10 to 16 years). It is noteworthy that the cementless components were used in less severe cases as $80 \%$ cover had to be available. Nevertheless, all the operations were performed by the same surgeon in two demographically-comparable groups of patients, with a minimum ten-year follow-up. There have been a few studies examining the outcome of the acetabular component in THR for congenital hip disease, in relation to the type of the deformity, ${ }^{5,20-28}$ but to our knowledge no evaluation of different surgical techniques has been reported.

The present study shows a significant statistical difference in the aseptic loosening of the acetabular component between the two methods. There are several reasons for 
this. Cotyloplasty was used in more deficient hips. By definition, this technique results in weaker bone for fixation and the offset-bore component was required in the majority of those cases. Chougle et $\mathrm{al}^{26}$ also noticed a higher rate of loosening with the use of offset acetabular components in similar circumstances to our own. The offset component, despite providing almost $10 \mathrm{~mm}$ thickness of polyethylene in its upper weight-bearing part, revealed a higher rate of loosening, probably because of impingement of the neck of the stem against the rim of the component, as wear of the polyethylene increased. ${ }^{26}$

The revision rate for the cementless group was increased when liner exchange due to wear and peri-acetabular osteolysis was included. The excellent fixation achieved with cementless components used in the 1990s, but with an increased revision rate due to problems with the liner and osteolysis, has been described in the Swedish hip register. ${ }^{29}$

It has been suggested that modular cementless acetabular components contribute to the increased wear that is a leading cause of aseptic loosening. ${ }^{30-33}$ In our study, the mean linear rate of wear of the polyethylene in cemented nonmodular and cementless modular acetabular components was not statistically significantly different. Although modularity does not seem in itself to increase linear wear notably or the amount of debris generated, it may provide, through backside wear, new pathways of access for particulate debris to reach the host bone. ${ }^{34}$

The effect of modularity of the femoral component on the outcome of the acetabular component has also been a matter for concern. It has been suggested that such designs could increase polyethylene wear through fretting, corrosion and third-body wear. ${ }^{35}$ In our study, the mean rate of wear of the polyethylene in both cemented and cementless acetabular components articulating with modular and monoblock femoral components was not statistically significantly different $(\mathrm{p}=0.41)$.

It has been reported that a polyethylene thickness of $5 \mathrm{~mm}$ or less in metal-backed components could lead to unsatisfactory results. ${ }^{36,37}$ However, in our study we found no correlation between the thickness of the polyethylene and the failure rate of the cementless acetabular components.

The association between wear rate and osteolysis in THR has been well documented by Dumbleton, Manley and Edidin. ${ }^{38}$ These authors concluded that osteolysis is observed rarely at a mean annual rate of wear $<0.1 \mathrm{~mm} / \mathrm{year}$. In our study, the mean annual wear in both cemented and cementless acetabular components presenting with osteolysis was $>0.15 \mathrm{~mm} /$ year. Patterns of osteolysis differ in association with cemented and cementless acetabular components. ${ }^{12,39}$ In our series, as in those previously mentioned, ${ }^{12,39}$ linear osteolysis was present mainly in association with cemented acetabular components, and expansile osteolysis in association with cementless components.

In our patients the overall survival of the shell/liner of the cementless components was less than that of the cemented components. However, the use of cementless metal-backed components, without augmentation of the superolateral aspect of the acetabular rim, is preferred when at least $80 \%$ cover of the implant with host bone can be obtained, because it provides a secure and lasting fixation. In the event of failure of the liner in the presence of a well-fixed metal shell, it is possible to undertake early intervention with exchange of the worn liner prior to the development of extensive osteolysis. The introduction of improved designs with a more stable locking mechanism, the use of the crosslinked polyethylene and the potential to use hard-on-hard bearings may lead to longer survival of the cementless components used for reconstruction of the acetabulum. Cotyloplasty remains a reliable alternative in selected cases. ${ }^{1,5}$

The authors wish to thank G. Kourlaba for her contribution to the statistical analysis of this study.

No benefits in any form have been received or will be received from a commercial party related directly or indirectly to the subject of this article.

\section{References}

1. Hartofilakidis G, Stamos K, Karachalios Th, loannidis TT, Zacharakis N. Congenital hip disease in adults: classification of acetabular deficiencies and operative treatment with acetabuloplasty combined with total hip arthroplasty. J Bone Joint Surg [Am] 1996;78-A:683-92.

2. Harris WH, Crothers $\mathbf{0}, \mathbf{O}$. J. Total hip replacement and femoral-head bone-grafting for severe acetabular deficiency in adults. J Bone Joint Surg [Am]1977;59-A:7529.

3. Russotti GM, Harris WH. Proximal placement of the acetabular component in total hip arthroplasty: a long-term follow-up study. J Bone Joint Surg [Am]1991;73-A:58792

4. Jasty M, Anderson MJ, Harris WH. Total hip replacement for developmental dysplasia of the hip. Clin Orthop 1995;311:40-5.

5. Hartofilakidis G, Karachalios Th. Total hip arthroplasty for congenital hip disease. J Bone Joint Surg [Am] 2004;86-A:242-50.

6. Hartofilakidis G, Stamos K, Karachalios Th. Treatment of high dislocation of the hip in adults with total hip arthroplasty: operative techniques and long-term clinical results. J Bone Joint Surg [Am] 1998;80-A:510-17.

7. Charnley J. Low friction arthroplasty of the hip: theory and practice. New York: Springer-Verlag, 1979.

8. Livermore J, Ilstrup D, Morrey B. Effect of femoral head size on wear of the polyethylene acetabular component. J Bone Joint Surg [Am] 1990;72-A:518-28.

9. Charnley J, Halley DK. Rate of wear in total hip replacement. Clin Orthop 1975;112:170-9.

10. Wroblewski BM. Direction and rate of socket wear in Charnley low-friction arthroplasty. J Bone Joint Surg [Br] 1985;67-B:757-61.

11. DeLee JG, Charnley J. Radiological demarcation of cemented sockets in total hip replacement. Clin Orthop 1976;121:20-32.

12. Zicat B, Engh CA, Gokeen E. Patterns of osteolysis around total hip components inserted with and without cement. J Bone Joint Surg [Am] 1995;77-A:432-9.

13. Schmalzried TP, Kwong LM, Jasty $\mathbf{M}$, et al. The mechanism of loosening of cemented acetabular components in total hip arthroplasty: analysis of specimens retrieved at autopsy. Clin Orthop 1992;274:60-78

14. Kaplan E, Meier P. Nonparametric estimation from incomplete observations. J Am Stat Assoc 1958;53:457-81

15. Pagnano W, Hanssen AD, Lewallen DG, Shaughnessy WJ. The effect of superior placement of the acetabular component on the rate of loosening after total hip arthroplasty. J Bone Joint Surg [Am] 1996;78-A:1004-14

16. Karachalios Th, Hartofilakidis G, Zacharakis N, Tsekoura M. A 12-18-year radiographic follow-up study of Charnley low-friction arthroplasty: the role of center of rotation. Clin Orthop 1993;296:140-7.

17. Harris WH. Management of the deficient acetabular using cementless fixation without bone grafting. Orthop Clin North Am 1993;24:663-5.

18. Mulroy RD Jr, Harris WH. Failure of acetabular autogenous grafts in total hip arthroplasty: increasing incidence: a follow-up note. J Bone Joint Surg [Am] 1990;72A:1536-40.

19. Goldberg VM, Stevenson S. The biology of bone grafts. Semin Arthroplasty 1993:4:58-63. 
20. Crowe JF, Mani VJ, Ranawat CS. Total hip replacement in congenital dislocation and dysplasia of the hip. J Bone Joint Surg [Am] 1979;61-A:15-23.

21. Numair J, Joshi AB, Murphy JC, Porter ML, Hardinge K. Total hip arthroplasty for congenital dysplasia or dislocation of the hip: survivorship analysis and long-term results. J Bone Joint Surg [Am] 1997;79-A:1352-60.

22. Haddad FS, Masri BA, Garbuz DS, Duncan CP. Primary total replacement of the dysplastic hip. J Bone Joint Surg [Am] 1999;81-A:1462-82.

23. Jaroszynski G, Woodgate I, Saleh K, Gross A. Total hip replacement for the dislocated hip. J Bone Joint Surg [Am] 2001;83-A:272-82.

24. Chougle A, Hemmady MV, Hodgkinson JP. Severity of hip dysplasia and loosening of the socket in cemented total hip replacement: a long-term follow-up. J Bone Joint Surg [Br]2005;87-B:16-20.

25. Rozkydal Z, Janícek P, Smíd Z. Total hip replacement with the CLS expansion shell and a structural femoral head autograft for patients with congenital hip disease. $J$ Bone Joint Surg [Am] 2005;87-A:801-7.

26. Chougle A, Hemmady MV, Hodgkinson JP. Long-term survival of the acetabular component after total hip arthroplasty with cement in patients with developmental dysplasia of the hip. J Bone Joint Surg [Am] 2006;88-A:71-9

27. Eskelinen A, Helenøus I, Remes V, et al. Cementless total hip arthroplasty in patients with high congenital hip dislocation. J Bone Joint Surg [Am] 2006;88-A:8091.

28. Hampton BJ, Harris WH. Primary cementless acetabular components in hips with severe developmental dysplasia or total dislocation: a concise follow-up at an average of sixteen years, of a previous report. J Bone Joint Surg [Am] 2006;88-A:1549-52

29. Malchau H, Herberts P, Eisler T, Garellick G, Söderman P. The Swedish Total Hip Replacement Register. J Bone Joint Surg [Am] 2002;84-A:2-20.
30. McCombe P, Williams SA. A comparison of polyethylene wear rates between cemented and cementless cups: a prospective, randomized trial. J Bone Joint Surg [Br] 2004:86-B:344-9.

31. Huk OL, Bansal M, Betts F, et al. Polyethylene and metal debris generated by nonarticulating surfaces of modular acetabular components. J Bone Joint Surg [Br] 1994;76-B:568-74.

32. Kurtz SM, Ochoa JA, White CV, Srivastav S, Cournoyer J. Backside nonconformity and locking restrains affect liner/shell load transfer mechanisms and relative motion in modular acetabular components for total hip replacement. J Biomech 1998;31:431-7.

33. Fehring T, Smith SE, Braun ER, et al. Motion at the modular acetabular shell and liner interface: a comparative study. Clin Orthop 1999;367:306-14.

34. Kurtz SM, Ochoa JA, Hovey CB, White CV. Simulation of initial frontside and backside wear rates in modular acetabular component with multiple screw holes. $J$ Biomech 1999;32:967-76.

35. Urban RM, Jacobs JJ, Gilbert JL, Galante J0. Migration of corrosion products from modular hip prostheses: particle microanalysis and histopathologic fndings. $J$ Bone Joint Surg [Am] 1994;76-A:1345-59.

36. Bartel DL, Bicknell VL, Wright TM. The effect of conformity, thickness and material on stresses in ultra-high molecular weight components for total joint replacement. J Bone Joint Surg [Am] 1986;68-A:1041-51.

37. Berry DJ, Barnes CL, Scott RD, Cabanela ME, Poss R. Catastrophic failure of the polyethylene liner of uncemented acetabular components. J Bone Joint Surg [Br] 1994;76-B:575-8.

38. Dumbleton JH, Manley MT, Edidin AA. A literature review of the association between wear rate and osteolysis in total hip arthroplasty. J Arthroplasty 2002;17:649-61.

39. Maloney WJ, Galante J0, Anderson M, et al. Fixation, polyethylene wear, and pelvic osteolysis in primary total hip replacement. Clin Orthop 1999;369:157-64. 